Elsevier Editorial System(tm) for Respiratory Physiology \& Neurobiology

Manuscript Draft

Manuscript Number:

Title: Oxygen-sensitive Kv channels in the carotid body

Article Type: Special Issue

Section/Category:

Keywords: Carotid body; hypoxia, potassium channels, chemoreception, transduction mechanisms,

Corresponding Author: Dr Teresa Perez-Garcia, MD, PhD

Corresponding Author's Institution: Universidad de Valladolid

First Author: José R López-López, MD, PhD

Order of Authors: José R López-López, MD, PhD; Teresa Perez-Garcia, MD, PhD

Manuscript Region of Origin:

Abstract: Hypoxic inhibition of $\mathrm{K}+$ channels has been documented in many native chemoreceptor cells, and is crucial to initiate reflexes directed to improve tissue 02 supply. In the carotid body (CB) chemoreceptors, it is a general consensus regarding the facts that a decrease in po2 leads to membrane depolarization, increase of Ca2+ entry trough voltage-dependent Ca2+ channels and Ca2+-dependent release of neurotransmitters. Central to this pathway is the modulation by hypoxia of $\mathrm{K}+$ channels that triggers depolarization. However, the details of this process are still controversial, and even the molecular nature of these oxygen-sensitive $\mathrm{K}+$ (KO2) channels in the $\mathrm{CB}$ is hotly debated. Clearly there are inter-species differences, and even in the same preparation more that one KO2 may be present. Here we recapitulate our present knowledge of the role of voltage dependent $\mathrm{K}+$ channels as KO2 in the CB from different species, and their functional contribution to cell excitability in response to acute and chronic exposure to hypoxia. 
Dear Dr Scheid:

We have been very pleased to accept Drs. Kumar and Prabhakar invitation to contribute to a Special Issue on the physiology an pathophysiology of the carotid body. Following their instructions, we have written a review paper focused on the role of voltagedependent potassium channels as oxygen-modulated ion channels in the carotid body. We have tried to make an up to date account of all the data available in the literature to provide an overview of our knowledge regarding the presence, the molecular and functional characterization and the role in oxygen chemotransduction in the carotid body of these channels.

This review is an original work that has notbeen published elsewhere, co-authored by Dr. J.R. López-López and myself.

Sincerely yours

Dr. M.T. Pérez-García 
Figure1

Click here to download high resolution image

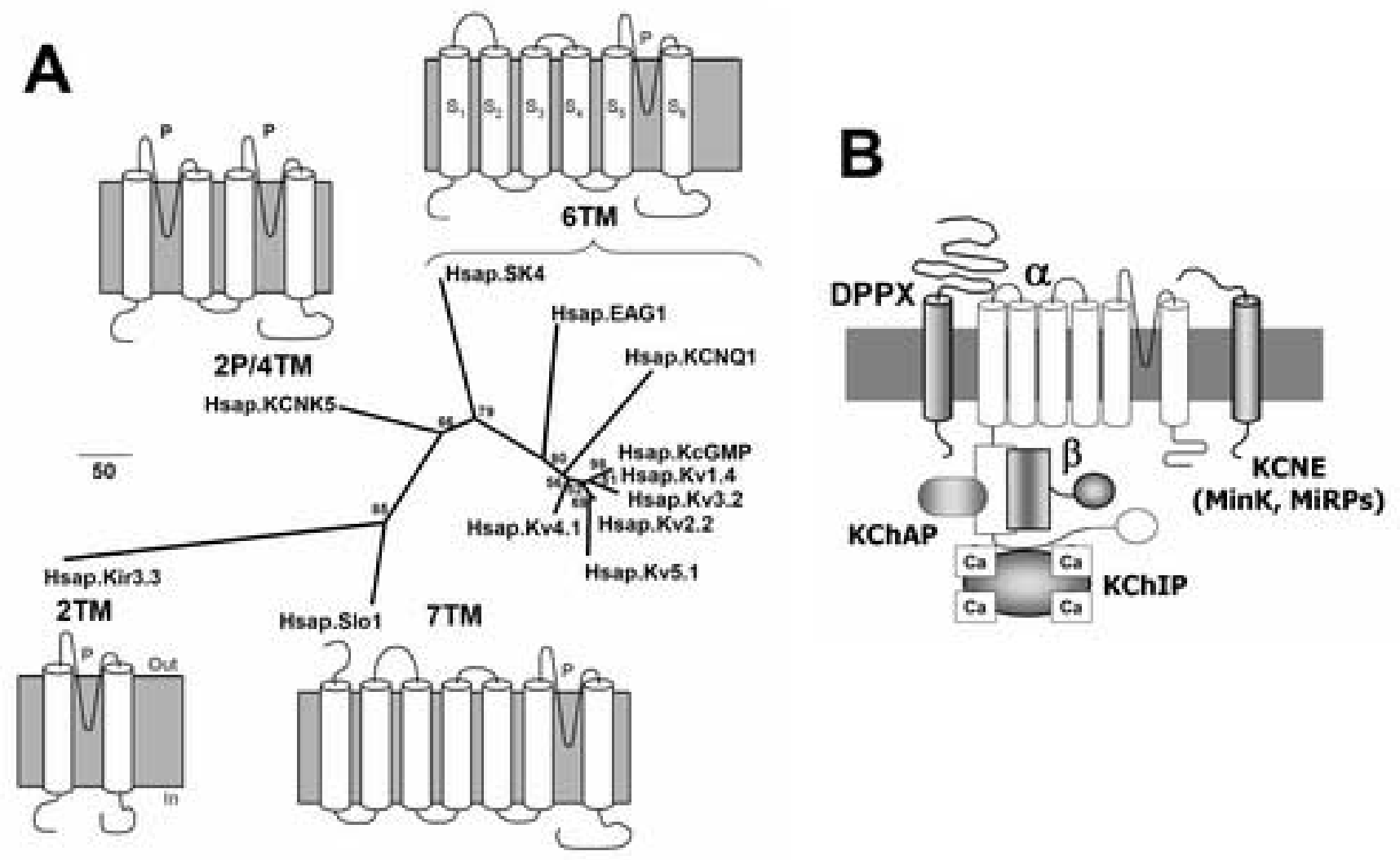


Figure2

Click here to download high resolution image

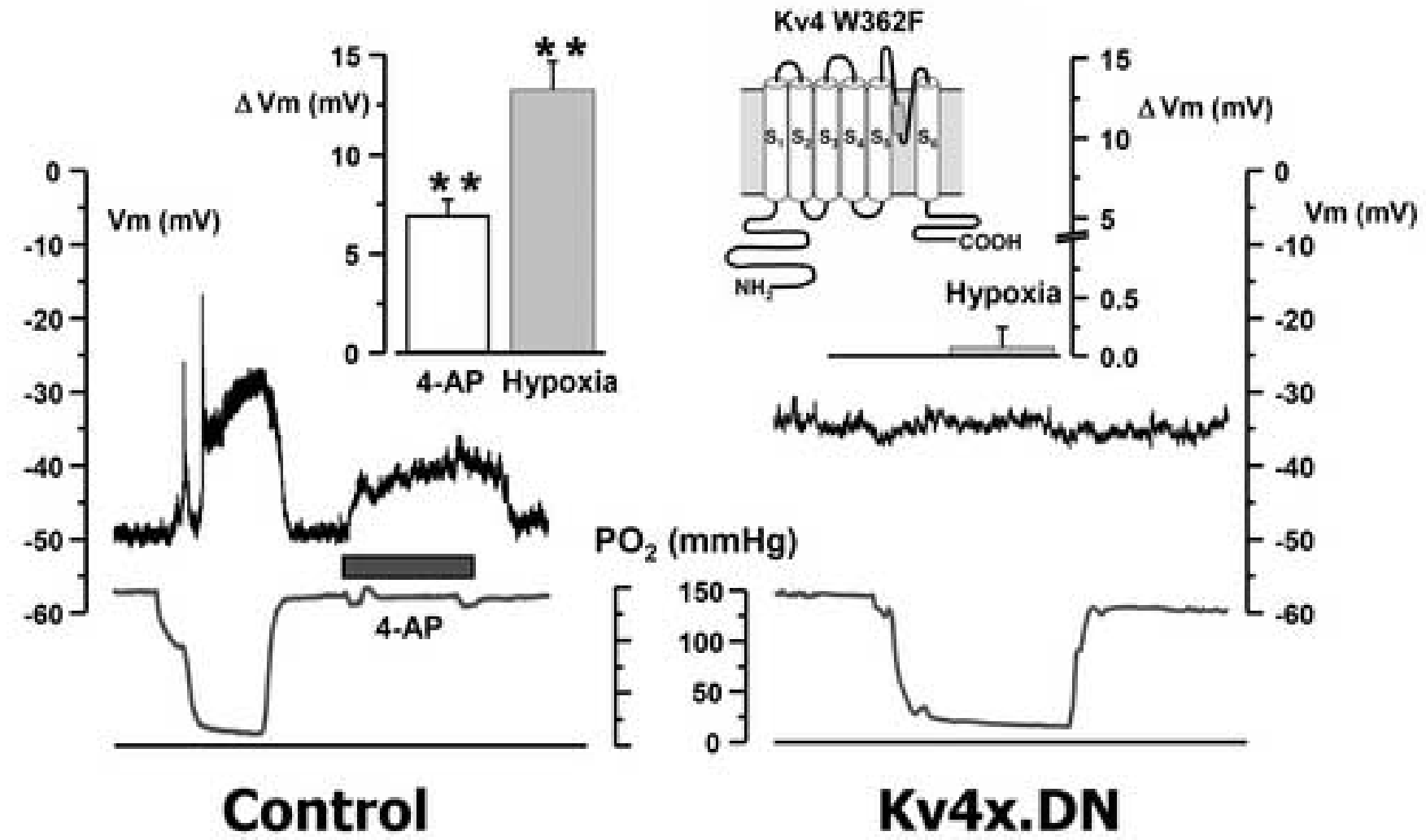


Figure 3
Click here to download high resolution image

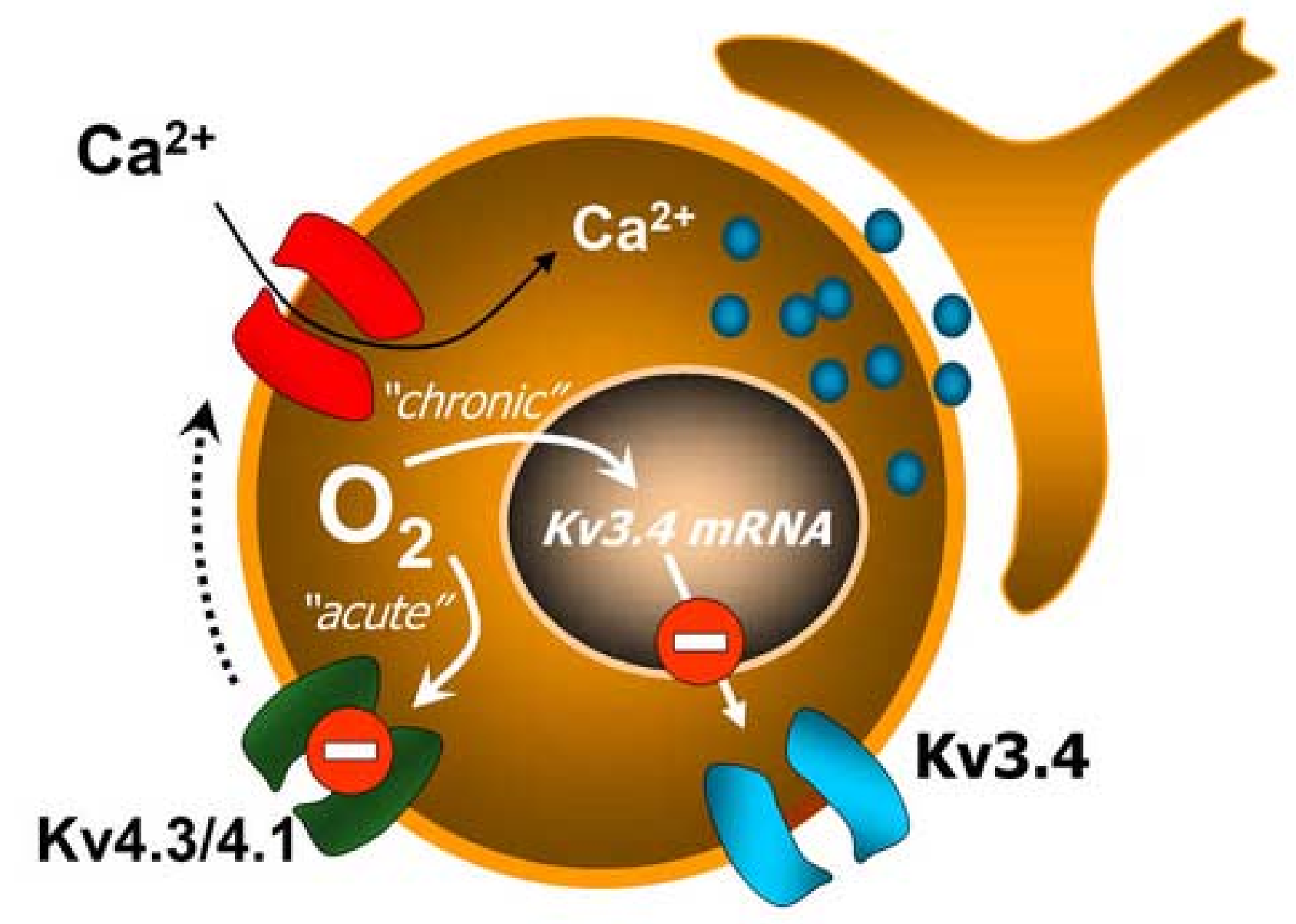




\section{Oxygen sensitive Kv channels in the carotid body}

José Ramón López-López and M. Teresa Pérez-García

Departamento de Bioquímica y Biología Molecular y Fisiología, Facultad de Medicina e Instituto de Biología y Genética Molecular (IBGM), Universidad de Valladolid y Consejo Superior de Investigaciones Científicas, Valladolid, Spain

Correspondence:

Dr. M.Teresa Pérez-García

Departamento de Fisiología

Universidad de Valladolid

Edificio IBGM

c/ Sanz y Forés s/n

47003 Valladolid SPAIN

Tel. 34983184590

FAX 34983423588 / 34983184800

e-mail tperez@ibgm.uva.es 


\section{Abstract}

Hypoxic inhibition of $\mathrm{K}^{+}$channels has been documented in many native chemoreceptor cells, and is crucial to initiate reflexes directed to improve tissue $\mathrm{O}_{2}$ supply. In the carotid body (CB) chemoreceptors, it is a general consensus regarding the facts that a decrease in $\mathrm{pO}_{2}$ leads to membrane depolarization, increase of $\mathrm{Ca}^{2+}$ entry trough voltage-dependent $\mathrm{Ca}^{2+}$ channels and $\mathrm{Ca}^{2+}$ dependent release of neurotransmitters. Central to this pathway is the modulation by hypoxia of $\mathrm{K}^{+}$channels that triggers depolarization. However, the details of this process are still controversial, and even the molecular nature of these oxygen-sensitive $\mathrm{K}^{+}\left(\mathrm{K}_{\mathrm{O} 2}\right)$ channels in the $\mathrm{CB}$ is hotly debated. Clearly there are inter-species differences, and even in the same preparation more that one $\mathrm{K}_{\mathrm{O} 2}$ may be present. Here we recapitulate our present knowledge of the role of voltage dependent $\mathrm{K}^{+}$channels as $\mathrm{K}_{\mathrm{O} 2}$ in the $\mathrm{CB}$ from different species, and their functional contribution to cell excitability in response to acute and chronic exposure to hypoxia. 


\section{Introduction}

Aerobic organisms depend on oxygen for the production of energy and for biosynthetic reactions. Therefore, cells, tissues and organisms must be able to sense and respond to changes in the oxygen concentration of their environment. The response of mammalian cells to hypoxia is crucial for their survival, allowing cells to cope with a low oxygen environment. Among those responses to hypoxia, the ones of specialized cells located in chemosensory organs (carotid bodies, pulmonary neuroepithelial bodies, pulmonary artery smooth muscle among others) are unique as they differ both quantitative and qualitatively from the general self-defense reaction of the organism against low oxygen. The specific hypoxic response of these chemosensitive cells is rapid (seconds to minutes), has a lower threshold, shows little or no adaptation during the entire period of hypoxia, and associates with an increase in their metabolic activity leading to changes in their excitability, contractility or secretory activity. All these features are specializations directed to prevent hypoxia in the entire organism, and thus, to warrant homeostasis.

CB chemoreceptors participate in the ventilatory responses to acute and chronic hypoxia $(\mathrm{CH})$. Arterial hypoxemia increases breathing within seconds, and $\mathrm{CB}$ chemoreceptors are the principal contributors to this reflex hyperventilatory response, as hypoxia induces release of neurotransmitters from $C B$ chemoreceptor cells that increase the activity of the afferent chemosensory fibers (Gonzalez, C. et al. 1994). Central to the cardiorespiratory responses to hypoxia in most chemosensory tissues is the rapid inhibition of ion channels. In the $\mathrm{CB}$, hypoxia depolarizes chemoreceptor cells by inhibiting $\mathrm{K}^{+}$ channels, leading to the activation of voltage-dependent $\mathrm{Ca}^{2+}$ channels, $\mathrm{Ca}^{2+}$ 
influx and exocytosis. Although this general mechanism seems to be present in all $\mathrm{O}_{2}$-sensitive tissues (Youngson, C. et al. 1993; Weir, E. K. et al. 1995), there are inter-species differences in the molecular nature of the $\mathrm{K}_{\mathrm{O} 2}$, and even in the same species more than one type of $\mathrm{K}_{\mathrm{O} 2}$ may be present (Peers, C. et al. 1995; Pérez-García, M. T. et al. 2000a; Patel, A. J. et al. 2001; Peers, C et al. 2001).

Direct inhibition by hypoxia of a $\mathrm{K}^{+}$channel was first demonstrated in chemoreceptor cells isolated from rabbit CB (Lopez-Barneo, J. et al. 1988) . Since then, many other $\mathrm{K}_{\mathrm{O} 2}$ have been found in several chemosensory preparations (Peers, C. 1997; Lopez-Barneo, J. et al. 2001; Patel, A. J. et al. 2001), and an intriguing as pect is the high degree of variability on the properties of these $\mathrm{K}_{\mathrm{O} 2}$ among different preparations, within the same preparation among different species, and within the same species among different developmental stages. Furthermore, there are evidences indicating that $\mathrm{K}_{\mathrm{O} 2}$ channels may be redundant, as more than one type of $\mathrm{K}_{\mathrm{O} 2}$ can coexist in the same preparation (Kemp, P.J. 2006), suggesting that the full hypoxic response of the cells may required the concerted action of more than one channel.

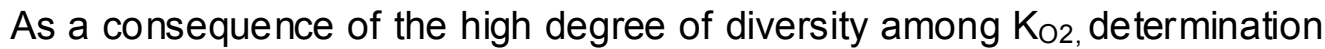
of the molecular identity of $\mathrm{K}_{\mathrm{O} 2}$ in native tissues as a previous step to explore the structural requirements for $\mathrm{O}_{2}$ sensing in these channels has been and active field of research within the last years. Several $\mathrm{K}^{+}$channel genes expressed in chemoreceptor cells have been identified, and some of them have been shown to behave as $\mathrm{K}_{\mathrm{O} 2}$ in heterologous expression systems. We have focused this review in those $\mathrm{K}_{\mathrm{O} 2}$ that produce voltage dependent $\mathrm{K}^{+}$currents $(\mathrm{Kv})$, since $\mathrm{K}_{\mathrm{O} 2}$ mediating background $\mathrm{K}^{+}$currents or $\mathrm{Ca}^{2+}$ activated $\mathrm{K}^{+}$currents are reviewed in other articles in this issue (Buckler ref; Peers ref). In the case of 
$\mathrm{Kv}$ channels, the molecular identity of the native $\mathrm{K}_{\mathrm{O} 2}$ has proven to be controversial. Since Kv channels are a family of proteins with a large molecular diversity (Coetzee, W. A. et al. 1999), it is a great challenge to assign the actual molecular identity to the native current observed in intact cells. The difficulty not only comes from the large number of candidate subunits, but also from the fact that heteromultimers formed between different subunits from the same family could give rise to currents with similar kinetics. The complexity is further enhanced by the fact that the association of auxiliary subunits and interacting proteins also changes channel properties. Yet, determination of the molecular constituents of the native $\mathrm{K}_{\mathrm{O} 2}$ is an issue of capital importance to understand the molecular mechanisms of $\mathrm{O}_{2}$ detection in chemoreceptor cells, to establish their physiological role in the native tissues, and additionally to provide a physiological meaning to the reported $\mathrm{O}_{2}$ modulation of cloned channels expressed in heterologous systems (Hulme, J. T. et al. 1999; Perez-Garcia, M. T. et al. 1999; Conforti, L. et al. 2000).

\section{Molecular diversity of Kv channels}

$\mathrm{K}^{+}$channels are arranged in homo or heterotetramers of principal subunits $(\alpha)$, accompanied by evolutionarily unrelated auxiliary subunits. Principal subunits have been classified in several subfamilies according to their biochemical and electrophysiological features (reviewed by Coetzee, W. A. et al. 1999). They all share a common core of two transmembrane (TM) domains that flank a pore-forming $(\mathrm{P})$ region (Figure $1 \mathrm{~A})$. The P-region shows a conserved signature (the sequence motif TxxTxGYGD) that accounts for the ionic selectivity filter of $\mathrm{K}^{+}$channels. The basic $2 \mathrm{TM}$ core forms the complete 
subunit of some $\mathrm{K}^{+}$channels, like the inward rectifiers subfamily (Kir) and the bacterial KcsA channels. However, the common core is complemented with a variable number of TM domains, giving rise to three different topological types of $\mathrm{K}^{+}$channels $(2 \mathrm{P} / 4 \mathrm{TM}, 6 \mathrm{TM}$ and $7 \mathrm{TM})$ present in metazoans (Figure 1A). The fourth TM segment (S4) of $6 \mathrm{TM} \mathrm{K}^{+}$channels contains a stretch with positively charged amino acids every third position and this is considered the key element for voltage sensing. 6TM are classified into several subfamilies ( $\mathrm{Kv}, \mathrm{KCNQ}$, EAG, KcGMP, SK) according to their functional features (Hille, B. 2001).

The mammalian counterparts of the cloned $\mathrm{Kv} \alpha$ subunits of Drosophila known as Shaker, Shab, Shaw, and Shal are designated Kv1, Kv2, Kv3, and $\mathrm{Kv} 4$, respectively. The Kv naming system was based on deduced phylogenetic relationships where channels that shared $65 \%$ sequence identity were assigned to a particular subfamily (Gutman, G. A. et al. 2003). At present, a parallel nomenclature designated $\mathrm{KCN}$ was developed by the Human Genome Organization to serve as a mechanism for classifying existing and newly discovered genes within the $\mathrm{K}^{+}$channel superfamily. These four $\mathrm{Kv}$ channel subfamilies each consist of a number of members, including Kv1.1-1.9, Kv2.12.2, Kv3.1-3.4, and Kv4.1-4.3, In addition to this four subfamilies, there are other non-conducting a subunits, which include Kv5, Kv6, Kv8 and Kv9 subfamiles, that share greater sequence identity with Kv2 channels and can associate with them to modulate their function. Within a subfamily, a highly conserved T1 domain located in the hydrophilic amino-terminal region immediately preceeding the $S 1$ segment is the minimal requirement for subfamily-specific tetramerization of a-subunits. These T1 domains represent 'identity tags' that mediate subunit-subunit interactions for the Kv1 through Kv4 
subfamilies and prevent heteromeric assembly of subunits belonging to different subfamilies.

Several $\mathrm{K}^{+}$channel auxiliary subunits have been identified that affect cell surface expression or modify specific functional properties of the pore-forming $\alpha$ subunits (Figure 1B). The first ancillary subunits described that associate with Kv channel a subunits where called Kv $\beta$ subunits (Martens, J. R. et al. 1999; Biggin, P. C. et al. 2000). Members of the Kv $\beta$ gene family are cytosolic proteins which interact with the $\mathrm{NH}_{2}$-terminal domains of $\mathrm{Kv} 1$ a subunits or the $\mathrm{COOH}$ terminal domains of some $\mathrm{Kv} 2$ and $\mathrm{Kv} 4$ a subunits, and serve numerous functions. They have been shown to increase current density by promoting $\alpha$ subunit surface expression early in biosynthesis, to alter the gating characteristics of some Kva subunits by conferring rapid channel inactivation, and to invest with redox sensitivity to $K v a-K v \beta$ channel complexes (Biggin, $P$. C. et al. 2000). Structurally, $K v \beta$ subunits couple in a 1:1 ratio with Kva subunits and form a tetramer that docks tightly with the cytoplasmic $\mathrm{N}$-terminal domain of Kv a subunits, the whole complex retaining a pseudo-fourfold symmetry.

The $\mathrm{K}^{+}$channel interacting protein (KChAP) is known to associate with $\mathrm{Kv} 1$, Kv2 and Kv4 family members to enhance cell surface expression without altering channel gating and thus it appears to function strictly as a chaperone (Kuryshev, Y. A. et al. 2001). This is not the case for members of the KCNE gene family (minK, KCNE1 and MiRPs, KCNE2-4) which have been shown to associate with a KCNQ (Kv1.7) and erg channels, but also with some members of the Kv family, such as Kv3.4 and Kv4.2. The gene product is a small (129aa) single membrane-spanning protein that was originally named MinK (minimal K channel protein). Association of these KCNE proteins with the $\mathrm{K}$ channel $\alpha$ 
proteins have been shown to have profound effects on channel gating and kinetics, drug sensitivity and voltage-dependent activation and inactivation (McCrossan, Z. A. et al. 2004). Also, for the Kv4 subfamily, several accesory subunits have been shown to co-immunoprecipitate and colocalize with Kv4 $\alpha$ subunits in heart and brain, indicating that they form stable complexes at the cell surface. Among those, three related proteins that specifically interact with Kv4 N-terminus were named $\mathrm{K}^{+}$channel interacting proteins 1-3 (KChIP1, KChIP2, KChIP3). KChIPs are cytoplasmic proteins that belong to the family of neuronal calcium sensor proteins, containing a conserved C-terminal core region and EF-hand domains (An, W. F. et al. 2000). The presence of the EFhand domains suggests the possibility that KChIP association may confer $\mathrm{Ca}^{2+}$ regulation to the function of Kv4 channels. Functionally, KChIP are shown to be integral auxilliary subunits that alter the membrane presentation of Kv4 channels in a chaperone-like way and also modulate their gating properties. However, co-expression of Kv4 a subunits with KChIP does not fully recapitulate the kinetics of native currents. It has recently been shown that Kv4 channels also interact with certain dipeptidyl aminopeptidase (DPPX) proteins and that a complex involving DPPX, Kv4 $\alpha$ and KChIPs reconstitutes the properties of native $\mathrm{Kv} 4 \mathrm{~K}^{+}$channels. Dipeptidyl aminopeptidases (DPP6 and DPP10, or DPPX and DDPY) are closely related to a family of non-classical serine proteases, but do not exhibit catalytic activity. DPP6 and DPP10 enhance Kv4.1 and Kv4.2 surface expression when co-expressed in oocytes and modulate the gating properties of these channels (Jerng, H. H. et al. 2004).

This brief overview of $\mathrm{Kv}$ channels structure provides some clues to understand the large functional heterogeneity of $\mathrm{K}$ currents. Their diversity 
originates partly from the large number of genes that encode $\mathrm{K}^{+}$channel $\alpha$ subunits, but also from alternative splicing, heteromeric assembly of poreforming a subunits, RNA editing and post-transcriptional modifications. This multiplicity, displayed as a wide variability in gating kinetics, conductance, ion selectivity and pharmacology, is augmented by the interaction of $\mathrm{K}^{+}$channels with their numerous ancillary proteins. In fact, in the light of recent findings ion channels can be envisioned as heteromeric, dynamically-assembled multiprotein complexes, to such extent that even though a subunits suffice to form a functional pore, it is not clear whether they actually do so in native tissues (Jerng, H. H. et al. 2004; McCrossan, Z. A. et al. 2004).

\section{Kv channels and oxygen-sensitivity in the CB}

The effect of oxygen tension modulating a votage-gated outward $\mathrm{K}^{+}$current in dissociated rabbit CB chemoreceptor cells (Lopez-Barneo, J. et al. 1988) propelled several groups to the electrophysiological characterization of this preparation, CB chemoreceptor cells. The results obtained are somewhat puzzling as they show important differences in the functional properties of CB chemoreceptor cells form different species and at different stages of development; besides, in spite of $\mathrm{K}_{\mathrm{O} 2}$ being consistently found in all preparations, their electrophysiological and pharmacological profile also varies within species (see also Peers, ref in this issue, and Buckler, ref in this issue).

\section{Kv channels in rabbit $C B$}

In rabbit carotid body, a series of studies both in whole-cell and in excised patch preparations reveal the presence of three components in the whole-cell 
$\mathrm{K}^{+}$currents: a large-conductance $\mathrm{Ca}^{2+}$-activated current, a small conductance non-inactivating current and a small conductance fast inactivating current. Of these, only the latter $\mathrm{K}^{+}$current is inhibited by hypoxia. Hypoxia inhibits this fast inactivating current ( $\mathrm{K}_{\mathrm{O} 2}$ channels) in a reversible manner, by decreasing its open probability (Ganfornina, M. D. et al. 1992a). As the inhibition is also observed in excised membrane patches in the absence of intracellular mediators, a direct effect of hypoxia on $\mathrm{K}_{\mathrm{O} 2}$ or on a closely associated membrane protein was suggested (reviewed in Peers, C. 1997). More detailed kinetic and pharmacological characterization of $\mathrm{Kv}$ currents in rabbit carotid body have been provided by several studies (Ganfornina, M. D. et al. 1992b; López-López, J. R. et al. 1993). However, the minute size of the organ together with its structural complexity has delayed the attempts to establish the molecular identity of the currents by conventional molecular biology techniques. The use of dominant-negative constructs to probe the molecular nature of the $\mathrm{K}_{\mathrm{O} 2}$ represented a first step in that direction (Pérez-García, M. T. et al. 2000b). Dominant-negative constructs to block the expression of Kv1 (Kv1.xDN) and $\mathrm{Kv} 4$ (Kv4.xDN), as members of these two families contribute to transient outward currents in other preparations, were delivered into chemoreceptor cells by adenoviruses enabling ecdysone-inducible expression of the constructs. While infection of chemoreceptor cells with Kv1.xDN did not change the amplitude or the hypoxic sensitivity of $\mathrm{K}_{\mathrm{O} 2}$, infections with $\mathrm{Kv} 4 . \mathrm{xDN}$ suppressed transient $\mathrm{Kv}$ current in a time-dependent manner suggesting that native $\mathrm{K}_{\mathrm{O} 2}$ currents in rabbit $\mathrm{CB}$ are carried mainly by genes of the Kv4 subfamily. In addition, the observation that Kv4.xDN infection depolarizes CB chemoreceptor cells at rest and abolished hypoxia-induced depolarization suggest that Kv4 
currents contribute to set resting membrane potential in this preparation. A more detailed molecular characterization of the expression of $\mathrm{Kv} \alpha$ subunits that might underlie $\mathrm{K}_{\mathrm{O} 2}$ currents demonstrated the expression in rabbit $\mathrm{CB}$ chemoreceptor cells of Kv3.4, Kv4.1 and Kv4.3 at the mRNA and protein level. Kv4.2 was absent and Kv1.4 was only found in sensory nerve endings (Sanchez, D. et al. 2002). Electrophysiological experiments applying specific toxins or antibodies demonstrate that both $\mathrm{Kv} 3.4$ and $\mathrm{Kv} 4 . \mathrm{x}$ contribute to the fast inactivating $\mathrm{K}^{+}$current of chemoreceptor cells. However, while Kv4 subunits are homogeneously expressed in all chemoreceptor cells, Kv3.4 channels seem to be present only in a subset of cells. Furthermore, $\left[\mathrm{Ca}^{2+}\right]_{\mathrm{i}}$ measurements in dispersed CB cells under hypoxic conditions followed by immunocytochemical detection of Kv3.4 and Kv4.3 demonstrated that the presence of Kv3.4 in the chemoreceptor cell membrane is not required for the low $\mathrm{PO}_{2}$ response. The results of this work lead to conclude that, due to their ubiquitous expression in chemoreceptor cells together with their electrophysiological properties, Kv4.1, $\mathrm{Kv} 4.3$, or their heteromultimers are the molecular correlate of the $\mathrm{K}_{\mathrm{O} 2}$ currents in rabbit CB. Immunological blockade of $\mathrm{K}^{+}$channels to analyze the effect of antiKv3.4 or anti-Kv4.3 on the amplitude of the transient outward currents and their hypoxic sensitivity further supports this conclusion (Lopez-Lopez, J. R. et al. 2003). In patch-clamp experiments, both antibodies produced a significant reduction in the amplitude of the current demonstrating that these subunits are structural components of the channels that contribute to the fast inactivating $\mathrm{K}^{+}$ current. After blocking Kv subunit-specific components, hypoxia could still decrease the remaining $\mathrm{K}^{+}$current in a significant manner. However, while antiKv3.4 antibody treatment does not modify in a significant way the magnitude of 
hypoxic inhibition of $\mathrm{K}^{+}$current, in the presence of anti-Kv4.3 antibody this inhibition is significantly reduced, indicating that Kv4.3, but not Kv3.4 channels, contribute to the $\mathrm{K}_{\mathrm{O} 2}$ currents. All these studies allow to conclude that $\mathrm{Kv} 4$ channels are the molecular correlate of $\mathrm{K}_{\mathrm{O} 2}$ originally described in rabbit $\mathrm{CB}$ chemoreceptor cells.

However, several important questions regarding the role of these channels in the chemosensory response of the organ still remain. One question of paramount interest is to determine if hypoxic inhibition of these channels is the only trigger of the chemoreceptor signalling cascade. As mentioned above, the effect of hypoxia on rabbit CB chemoreceptor cells has been proposed to be mediated by a depolarizing shift in the resting membrane potential which leads to $\mathrm{Ca}^{2+}$ entry and neurotransmitter release. The activation threshold of Kv4 subunits (around $-50 \mathrm{mV}$ ) makes them good candidates for controlling membrane potential, and data suggesting this role has been provide by the effect of adenoviral infection with the Kv4 dominant-negative (Pérez-García, M. T. et al. 2000b). Selective removal of the transient outward current is able to abolish the hypoxia-induced depolarization of the cells, and both hypoxia and 4aminopirydine $(1 \mathrm{mM})$ can induce depolarization of rabbit CB chemoreceptor cells. Although other targets for the effect of hypoxia on resting membrane potential can not be excluded, the fact that all these manoeuvres (AdKv4.xDN infection, low $\mathrm{pO}_{2}$ and $1 \mathrm{mM}$ 4-AP application) are able to inhibit transient outward currents on the one hand and to depolarize CB chemoreceptor cells on the other, suggests a causal relationship between this two effects, and thereby a contribution of the Kv4-mediated transient outward current to set the normal resting membrane potential of rabbit CB chemoreceptor cells. 
With respect to the possible role of $\mathrm{Kv} 3.4$, it is known that the presence of Kv3 channel subunits enables excitable cells to achieve fast repolarization of action potentials (reviewed by Rudy, B. et al. 2001), which in turn permits the repetitive firing of action potentials at high frequency. $C B$ chemoreceptor cells are known to fire action potentials whose frequency increases with exposure to low $\mathrm{PO}_{2}$ (López-López, J. R. et al. 1989). The expression of Kv3.4 could be involved in amplifying the hypoxic signal by increasing the firing frequency upon depolarization by low $\mathrm{PO}_{2}$. In this scheme, an $\mathrm{O}_{2}$-dependent blockade of the Kv3.4 should result in a prolonged spike repolarization, which in turn would decrease firing frequency. Thus, all the evidence gathered so far suggests that $\mathrm{Kv} 3.4$ would not be the $\mathrm{O}_{2}$-sensitive channel component of the chemoreception cascade, but instead would play a modulatory role in chemoreceptor cell excitability. In fact, some recent reports implicate Kv3.4 channel expression in the adaptation of chemoreceptor cells responses in several physiopathological situations (see bellow).

Aside for these $\mathrm{Kv}$ channels, functional expression of other $\mathrm{K}^{+}$channels have been reported in rabbit $\mathrm{CB}$ chemoreceptor cells, although the available data is scatter, and none of them have been demonstrated to participate in oxygen chemoreception. HERG-like currents have been shown to contribute to resting membrane potential, but their modulation by hypoxia has not been assessed (Overholt, J. L. et al. 2000). The expression of maxi-K currents has been consistently found in several preparations of rabbit $\mathrm{CB}$ chemoreceptor cells, using either electrophysiological or pharmacological tools. The amplitude of the se currents exhibits a high cell to cell variability (Pérez-García, M. T. et al. 1992) and more importantly, they are not modulated by oxygen in this 
preparation, which is in marked contrast with the proposed role of these channels in rat CB (see chapter by Peers in this issue). Finally, some pharmacological studies suggest the presence of ATP-dependent $\left(\mathrm{K}_{\mathrm{ATP}}\right)$ and two-pore domain (TASK-like) $\mathrm{K}^{+}$channels, but there are not direct studies of these channels and no data regarding their role on hypoxic chemotransduction (Takahashi, T. et al. 2005).

\section{Kv channels in rat $C B$}

$\mathrm{K}_{\mathrm{O} 2}$ currents have also been described in chemoreceptor cells from neonatal and adult rat $\mathrm{CB}$. At least, there appear to be two distinct $\mathrm{K}^{+}$channels that respond to hypoxia thus causing depolarisation; firstly a high-conductance, $\mathrm{Ca}^{2+}$-activated $\mathrm{K}^{+}$(maxiK or BK) channel (Peers, C. 1990; Pardal, R. et al. 2000; Riesco-Fagundo, A. M. et al. 2001) and secondly, an acid-sensitive tandem P domain $\mathrm{K}^{+}$channel, TASK (Buckler, K. J. et al. 2000). The properties of these two channels and their functional role in hypoxic signalling are described in detail in the chapters by Peers and Buckler in this issue. Although Kv currents are also present in this preparation, it is out of doubt that they do not represent the molecular correlate of $\mathrm{K}_{\mathrm{O} 2}$ currents; instead, they may serve other physiological functions in the organ. In adult rat CB chemoreceptor cells, outward currents are carried mainly by $\mathrm{K}^{+}$, and two different components can be distinguished: $\mathrm{A} \mathrm{Ca} \mathrm{Ca}^{2+}$-dependent $\mathrm{K}^{+}$(maxiK) current sensitive to $\mathrm{Cd}^{2+}$ and charybdotoxin (ChTX) and reversibly inhibited by hypoxia, and a $\mathrm{Ca}^{2+}$ insensitive, voltage-dependent $\mathrm{K}^{+}$current (IKv). IKv is blocked by TEA in the low $\mathrm{mM}$ range and is relatively insensitive to low concentrations of 4-AP. This pharmacological profile, together with its kinetic properties (slow voltagedependent activation and very slow biexponential and voltage-independent 
inactivation) define a classical delayed rectifier $\mathrm{K}^{+}$channel (López-López, J. R. et al. 1997), most likely of the Kv2 (Shab) subfamily, although no structural studies have been performed. The same two types of currents have been described in neonatal rat CB (Peers, C. et al. 1990). The relative contribution of these two components to fix resting membrane potential and consequently cell excitability is a key determinant of the altered response of the organ under physiological or physiopathological conditions. In this regard, changes on the relative expression of maxiK channels and IKv have been shown to correlate with the maturation of the response to hypoxia of the rat $\mathrm{CB}$ during development (Hatton, C. J. et al. 1997), and also provide an explanation to the sensitization of the response to acute hypoxic episodes after chronic hypoxia exposure in adult animals (Carpenter, E. et al. 1998) and to the blunting of the acute hypoxic responses in neonatal animals born in a chronically hypoxic environment (Wyatt, C. N. et al. 1995, see below). In this later situation, it has been shown that this blunting of the acute hypoxic response correlates with the decrease of functional maxiK channels and the lost of hypoxic-induced depolarization of chemoreceptor cells. However, the magnitude of hypoxic inhibition of $\mathrm{K}^{+}$ currents was unchanged, indicating that acute hypoxia was modulating another $\mathrm{K}^{+}$current $(\mathrm{IKv})$ that did not appear to influence resting membrane potential. As a corollary, it was suggested that chemoreceptor cells respond to hypoxia not because they possess specific $\mathrm{K}_{\mathrm{O} 2}$ channels, but because they possess (as yet unidentified) specialized intracellular $\mathrm{O}_{2}$-sensing mechanisms, which can couple to different $\mathrm{K}^{+}$channel types, an interesting proposal that could also help to explain the large molecular diversity of $\mathrm{K}_{\mathrm{O} 2}$. 


\section{Kv channels in mouse $C B$}

In the mouse CB initial studies have suggested important strain-dependent differences in the ventilatory responses to hypoxia, which seemed to have a correlate with differences in the structural and functional properties of the CB. Apart from the small size of the organ and its structural complexity and variability among strains, in this specie it has been found that the number of chemoreceptor is very low. Using a whole CB preparation (to preserve structural relationships) from DBA/2J strain (a hypoxia-responsive one) it has been shown the presence of outward $\mathrm{K}^{+}$currents that where reversibly inhibited by hypoxia and that could be classified in at least tree different types: delayed rectifier, A-type and $\mathrm{Ca}^{2+}$-activated $\mathrm{K}^{+}$currents (Yamaguchi, S. et al. 2004). In the presence of iberotoxin, hypoxia did not further inhibit $\mathrm{K}^{+}$currents, suggesting that $\mathrm{K}_{\mathrm{O} 2}$ currents in this strain are most likely trough maxiK channels (Otsubo, T. et al. 2006). These authors proposed that differential expression of $\mathrm{K}^{+}$currents could contribute to differences in hypoxia sensitivity, and in fact maxiK mRNA (both the pore-forming $\alpha$ subunit and two different $\beta$ subunits) seem to be more expressed in this DBA/2J strain than in $A / J$ strain (a nonresponsive one) although no quantification has been made.

A different approach to the characterization of the electrical properties of mouse CB chemoreceptor cells is the use of chemoreceptor cells in primary cultures obtained from a transgenic mouse expressing GFP under the control of tyrosine hydroxylase (TH) promoter (Sawamoto, Kazunobu et al. 2001). Immunocytochemical identification of TH in CB cell cultures reveals a good match with GFP positive cells (Perez-Garcia, M. T. et al. 2004). Furthermore, these cells show an increase in $\left[\mathrm{Ca}^{2+}\right]_{\mathrm{i}}$ in response to low $\mathrm{pO}_{2}$, demonstrating 
their ability to engender a physiological response. Whole-cell experiments demonstrated slow-inactivating $\mathrm{K}^{+}$currents with a bi-exponential kinetic of deactivation. TEA sensitivity of the currents identified also two different components ( $\mathrm{IC}_{50}$ of $17.8 \pm 2,8$ and $\left.940.0 \pm 14.7 \mu \mathrm{M}\right)$. Current amplitude decreased reversibly in response to hypoxia, which selectively affected the fast deactivating component. Hypoxic inhibition was also abolished in the presence of low $(10-50 \mu \mathrm{M})$ concentrations of TEA, suggesting that $\mathrm{O}_{2}$ interacts with the component of the current most sensitive to TEA. Molecular biology and immunocytochemical techniques identify the expression of Kv2.2, Kv3.1, Kv3.2 and $\mathrm{Kv} 3.3$ subunits at the mRNA and for all but Kv2.2 also at protein level within single chemoreceptor cells. The pharmacological profile of the hypoxia sensitive component of $\mathrm{Kv}$ current makes $\mathrm{Kv} 3$ subunits prime candidates for the molecular correlate of the native $\mathrm{K}_{\mathrm{O} 2}$ current.

Again, there are not studies on the functional contribution of these different $\mathrm{K}_{\mathrm{O} 2}$ currents to chemoreceptor cells excitability in mouse $\mathrm{CB}$. Further studies directed to explore the effect of hypoxia on resting membrane potential as well as the presence and possible $\mathrm{O}_{2}$ modulation of other families of $\mathrm{K}$ channels (and their accessory subunits) will allow to determine the molecules involved in the hypoxic transduction cascade. However, this characterization will benefit of the possibility of using transgenic mice with deletion of some of the identified channels subunits as a tool to understand the contribution of these channels to excitability of the cells.

\section{Kv channels in cat $C B$}

In cultured cat CB cells, two types of cells were identified electrophysiologically, ones that had $\mathrm{K}_{\mathrm{O} 2}$ and others whose $\mathrm{K}^{+}$currents were not 
inhibited by hypoxia. However, these two types of cells were morphologically indistinguishable and the $\mathrm{K}^{+}$currents had similar pharmacological and kinetic properties (Chou, C. L. et al. 1996). They are non-inactivating outward $\mathrm{K}^{+}$ currents sensitive to mM TEA. Combination of electrophysiological studies with immunocytochemical characterization demonstrated that only the cells positive for tyrosine-hydroxylase ( $\mathrm{TH}$ ) possessed $\mathrm{K}_{\mathrm{O} 2}$, and that only those cells were depolarized under hypoxic exposure (Chou, C. L. et al. 1998). However, no further studies conducted to study the functional contribution of $\mathrm{K}_{\mathrm{O} 2}$ in these cells or their molecular correlates have been performed.

\section{Oxygen-modulated Kv channels in other preparations}

$\mathrm{K}_{\mathrm{O} 2}$ currents are surprisingly ubiquitous, as they have been found in many tissues and cells (not only specialized oxygen-sensitive ones), and incredibly heterogeneous in terms of their molecular nature, not to talk about the mechanisms of $\mathrm{O}_{2}$ regulation that is been covered in other chapters of this issue. Also in some of these preparations species-related differences in the nature of the $\mathrm{K}_{\mathrm{O} 2}$ channels have been described.

In the case of adrenal chromaffin cells, it has been described that they possess a developmentally regulated $\mathrm{O}_{2}$-sensing mechanis $\mathrm{m}$, similar to carotid body type I cells. The work by Thompson and colleagues (Thompson, R. J. et al. 1997) shows that rat adrenomedullary chromaffin cells possess $\mathrm{O}_{2}$-sensing mechanisms, similar to their neural crest counterparts in the carotid body, and that these mechanisms are present in cells from neonatal animals but dissapear during development. Electrophysiological experiments indicate that hypoxia is able to depolarize neonatal adrenal chromaffin cells and thus induce 
neurosecretory response (Thompson, R. J. et al. 1997). Both in rat and in mouse cells, $\mathrm{K}_{\mathrm{O} 2}$ currents included both $\mathrm{Ca}^{2+}$-dependent (maxiK) and $\mathrm{Ca}^{2+}$ independent, delayed rectifier type (IKv) (Thompson, R. J. et al. 1998; Thompson, R. J. et al. 2002). However, at least in the rat adrenal chromaffin cells, hypoxic inhibition of these two types of channels does not seem to account for cell depolarization, as this depolarization was unchanged in the presence of selective blockers of maxiK channels and was not fully prevented after blockade of IKv with TEA and 4-aminopyridines, suggesting the existence of additional $\mathrm{O}_{2}$-sensing mechanism that controls at least part of the initial depolarization or receptor potential during anoxia and that is insensitive to conventional blockers of Kv channels (Thompson, R. J. et al. 1998).

In neuroepithelial body (NEB) cells of foetal rabbit and neonatal human lungs the $\mathrm{H}_{2} \mathrm{O}_{2}$-sensitive channel $\mathrm{Kv3}$.3a has been shown to be co-expressed with the membrane components of the NADPH oxidase (gp91 phox and $\mathrm{p} 22^{\text {phox }}$ ), and to respond to hypoxia with a reversible inhibition (Wang, D. et al. 1996). Although it has been reported that hypoxia fails to inhibit NEB $\mathrm{K}^{+}$channels in gp9 $1^{\text {phox }}$ knock-out mice (Fu, X. W. et al. 2000), NADPH oxidase is, however, not a universal oxygen sensor, as hypoxic inhibition of $\mathrm{K}^{+}$channels in pulmonary artery smooth muscle cells is unaltered in oxidase knock-out animals (Patel, A. J. et al. 2001). Electrophysiological studies of "intact" NEB performed in fresh neonatal rabbit lung slices indicate that outward $\mathrm{K}^{+}$currents could be dissected into two components, a $\mathrm{Ca}^{2+}$-dependent and a $\mathrm{Ca}^{2+}$-independent, being both components roughly equally suppressed by hypoxia. A similar pattern of expression of $\mathrm{K}_{\mathrm{O} 2}$ currents have been also found in mouse NEB in lung slices (Fu, X. W. et al. 2000). 
In pulmonary artery smooth muscle cells (PASMC), based on what we know so far, $\mathrm{Kv}$ channels appear to be top candidates as the $\mathrm{K}_{\mathrm{O} 2}$ channels, although other types of $\mathrm{K}^{+}$and $\mathrm{Ca}^{2+}$ channels are also regulated by hypoxia (reviewed in Patel, A. J. et al. 2001; Yuan, J. X. 2001). The summary of the work of several laboratories, using different approaches, has provide compelling evidence indicating that $\mathrm{Kv} 2.1, \mathrm{Kv} 1.2, \mathrm{Kv} 1.5$ and $\mathrm{Kv} 3.1 \mathrm{~b}$, some of them probably as heteromultimers, may encode $\mathrm{K}_{\mathrm{O} 2}$ channels in PASMC. The finding of differential expression of several Kv channel auxiliary proteins such as Kv $\beta$ subunits and Kv9.3 subunits provide a new concept by strongly suggesting that these accessory subunits of the pore-forming Kva subunit as well as their heterologous assembly with different $\alpha$ subunits may play a critical role in determining the oxygen sensitivity of Kv channels in PASMC (Patel, A. J. et al. 2001; Yuan, J. X. 2001). The study of whether these subunits form the native Kv channels that are dominantly involved in the regulation of resting membrane potential and which channel subunit combinations have a physiological role in determining oxygen-sensitivity of PASMC constitute fields of intense research. However, in the last years is becoming more evident that there will not be only one $\mathrm{K}_{\mathrm{O} 2}$ channel in PASMC. Rather, the oxygen sensor responsible for hypoxic pulmonary vasoconstriction would be better defined as an oxygen-sensing system in which multiple "oxygen sensors" coordinate with each other and transduce hypoxic signals to different "effectors" (i.e., the different Kv channel $\alpha$ and $\beta$ subunit combinations) to ensure efficacy (Yuan, J. X. 2001).

Finally, it is noteworthy to point out that a number of studies have been focused to determine the sensitivity to hypoxia of recombinant $\mathrm{Kv}$ channel in heterologous expression systems, including Xenopus oocytes, mouse L-cell 
line, CHO cells, rat adrenal PC12 cells, COS- 7 cells, and HEK-293 cells (reviewed in Lopez-Barneo, J. et al. 2001; Patel, A. J. et al. 2001; Yuan, J. X.

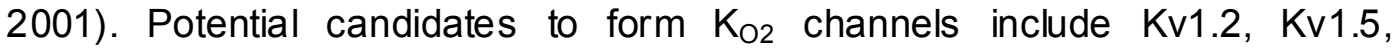
$\mathrm{Kv1.2/Kv1.5} \mathrm{Kv2.1} \mathrm{Kv2.1/Kv9.3} \mathrm{Kv3.1b,} \mathrm{Kv3.3} \mathrm{and} \mathrm{Kv4.2/Kv \beta 1.2.} \mathrm{In} \mathrm{all} \mathrm{cases,}$ acute hypoxia significantly reduces the $\mathrm{K}^{+}$currents generated by these channels, and their hypoxic sensitivity appears to be independent of the expression systems. These experiments with recombinant channels open the way to investigate hypoxic inhibition at the molecular level, providing important information to understand the molecular basis of oxygen-sensitivity by ion channels, as they contribute to resolve an issue of paramount importance, that is whether the channels can themselves directly act as $\mathrm{O}_{2}$ sensors.

\section{Role of carotid body Kv channels in chronic hypoxia adaptation}

Prolonged periods of hypoxia, either the ones experienced by healthy individuals at high altitude or as a consequence of cardiorespiratory disorders, result in significant cellular adaptation or remodelling, leading to changes in cellular excitability. Altered ion channel expression by chronic hypoxia $(\mathrm{CH})$ is an important component of this functional adaptation, contributing directly to the modified tissue response to hypoxia. The mechanisms by which $\mathrm{CH}$, as opposed to acute hypoxia, triggers altered functional expression of ion channels are of cardinal interest from a physiological point of view, since they probably contribute to adaptation to high altitude, but also and more importantly from a physiopathological perspective, as damage in certain respiratory and cardiovascular diseases is to a large extent secondary to prolonged exposure to low $\mathrm{O}_{2}$ levels. 
The ventilatory acclimatization to hypoxia is almost exclusively dependent on CB (Bisgard, G. E. 2000) were $\mathrm{CH}$ exposure induces profound morphological and neurochemical changes (Wang, Z. Y. et al. 2002) together with increased chemosensitivity. Reports concerning the effects of prolonged hypoxia on the acute hypoxic sensitivity of the $C B$ are mixed, and some discrepancies might be accounted for by species-dependent rates of adaptation of the $\mathrm{CB}$ to $\mathrm{CH}$. Long term exposure to hypoxia leads to an enhancement of acute hypoxic reactivity that within some time (weeks to years, depending on species) changes into a blunting of the response to acute hypoxia. As the chemotransduction cascade begins with the inhibition of $\mathrm{K}_{\mathrm{O} 2}$, it has been hypothesized that changes in the expression levels or in the $\mathrm{O}_{2}$ sensitivity of $\mathrm{K}_{\mathrm{O} 2}$ could contribute $\mathrm{CH}$ adaptations. In fact, in $\mathrm{PC} 12$ cells the effect of $\mathrm{CH}$ on the expression pattern of $\mathrm{K}^{+}$currents has been studied, and up-regulation of the $\mathrm{K}_{\mathrm{O} 2}$ current (Kv1.2) has been proposed as the mechanism of hypoxic sensitisation (Conrad, P. W. et al. 2001). Similarly, the changes in the expression of the $\mathrm{O}_{2}$-sensitive components of the $\mathrm{K}^{+}$current has been implicated in the loss of hypoxic sensitivity of pulmonary artery smooth muscle cells upon exposure to prolonged hypoxia (Platoshyn, O. et al. 2001; Pozeg, Z.I. et al. 2003). In the rat $C B$, blunting of the acute hypoxic response in animals born and raised under $\mathrm{CH}$ has been demonstrated to correlate with the downregulation of the $\mathrm{K}_{\mathrm{O} 2}$ current (maxiK channels, (Wyatt, C. N. et al. 1995). On contrast, in the rabbit $\mathrm{CB}$ chemoreceptor cells a different mechanism that results in modification of hypoxic sensitivity by $\mathrm{CH}$ without affecting the expression of $\mathrm{K}_{\mathrm{O} 2}$ channels has been described. $\mathrm{CH}$ in vitro is able to induce changes in the expression profile of $\mathrm{Kv}$ channels of chemoreceptor cells that 
lead to an increase of hypoxic sensitivity of $\mathrm{K}^{+}$currents (Kaab, S. et al. 2005). Exposure of $\mathrm{CB}$ primary cultures during $24-72 \mathrm{~h}$ to low levels of $\mathrm{O}_{2}(5 \% ; \sim 33$ $\mathrm{mmHg}$ ) produces a specific down-regulation of Kv3.4 channel (both at the protein and mRNA levels) that accounts for the decrease in the fast transient outward $\mathrm{K}^{+}$current that can be observed in the whole-cell experiments. Importantly, as the $\mathrm{K}_{02}$ current in this preparation has been identified as belonging to the $\mathrm{Kv} 4$ family, down-regulation of Kv3.4 gene leads to a decrease of the $\mathrm{O}_{2}$-insensitive component of the $\mathrm{K}^{+}$current, resulting in a more predominant role of $\mathrm{K}_{\mathrm{O} 2}$ in the total outward current, with the subsequent relative increase in the magnitude of acute low $\mathrm{PO}_{2}$-induced inhibition. Moreover, under $\mathrm{CH}$ conditions, acute hypoxia induced a significantly larger depolarization of resting membrane potential and consequently increased excitability, indicating that this ionic remodelling could explain $\mathrm{CH}$ sensitization. These results imply that in rabbit $\mathrm{CB}$ chemoreceptor cells acute and chronic hypoxia are both able to modulate ion channels, but exert their effects acting through different molecules: while acute exposure to hypoxia decreases the activity of Kv4 channels, prolonged hypoxia down-regulates Kv3.4 channels, and doing so increases the relative contribution of $\mathrm{Kv} 4$ channels to the total outward current (Figure 3). The data of Peers' group in rat CB (Carpenter, E. et al. 1998) could be reinterpret in a similar fashion, as they show that $\mathrm{CH}$ decreases $\mathrm{K}^{+}$current density because of a reduction of the $\mathrm{Ca}^{2+}$-insensitive $\mathrm{K}^{+}$ current (IKv) component without changes in the maxiK current amplitude. Their results also indicate that adult rat $\mathrm{CB}$ chemoreceptor cells undergo a selective suppression of $\mathrm{Ca}^{2+}$-insensitive, voltage-gated $\mathrm{K}^{+}$currents in response to $\mathrm{CH}$ in 
vivo, which results on an increased proportion of the $\mathrm{K}_{\mathrm{O} 2}$ current to the total currents.

Whilst this mechanism may participate in adaptive responses such as highaltitude acclimatization, such altered channel expression may also contribute to the onset of pathological disorders. In this regard, the same functional changes and the same remodelling of $\mathrm{Kv}$ channels (a decrease of $\mathrm{Kv} 3.4$ channels without changes in $\mathrm{Kv} 4$ expression) described under $\mathrm{CH}$ in rabbit $\mathrm{CB}$ (Kaab, S. et al. 2005) has been reported in rabbit CB from a model of congestive heart failure (Li, Yu Long et al. 2006). Chronically impaired cardiac output in this animal model might be sufficient to render a prolonged deprivation of oxygen delivery to chemoreceptor cells, a state akin to $\mathrm{CH}$, leading to activation of renin-angitotensin system in the $\mathrm{CB}$. The up-regulation by $\mathrm{CH}$ of this local angiotensin system contributes to altered sensitivity of $C B$ to acute hypoxia, as angiotensin II increases the sensitivity of $\mathrm{Kv}$ channels to hypoxia and the hypoxia-induced depolarization ( Li, Yu Long et al. 2006).

In general, while acute hypoxic responses occur on a time scale of seconds or less and involve the modification of pre-existing proteins, $\mathrm{CH}$ responses occur on a time scale of minutes or more and involve changes in gene expression leading to new protein synthesis. The discovery of the transcription factor HIF-1 has led to the delineation of molecular mechanisms of $\mathrm{O}_{2}$-regulated gene expression that are operative in all cells including those within the carotid body (see Lahiri, S. et al. 2006). Although HIF-1 mediated regulation of ion channels under $\mathrm{CH}$ have been shown in pulmonary artery smooth muscle cells (Aaronson, Philip I. 2006), data regarding its role in CB is still awaiting further experimentation. 


\section{Acknowledgements}

We thank D. Sánchez and MD Ganfornina for the development of the phylogenetic tree of $\mathrm{K}^{+}$channels (figure 1). This work was supported by Instituto de Salud Carlos III grants G03/045 (Red Heracles) and PI041044 (JRLL), Ministerio de Educación y Ciencia grant BFU2004-05551 (MTPG) and Junta de Castilla y León grant VA011C05. 


\section{References}

Aaronson,P.I., 2006. TRPC Channel Upregulation in Chronically Hypoxic Pulmonary Arteries: The HIF-1 Bandwagon Gathers Steam. Circ Res 98, 1465-1467.

An,W.F., Bowlby,M.R., Betty,M., Cao,J., Ling,H.P., Mendoza,G., Hinson,J.W., Mattsson,K.I., Strassle,B.W., Trimmer,J.S., and Rhodes,K.J., 2000. Modulation of Atype potassium channels by a family of calcium sensors. Nature 403, 553-556.

Biggin,P.C., Roosild,T., and Choe,S., 2000. Potassium channel structure: domain by domain. Curr. Opin. Struct. Biol. 10, 456-461.

Bisgard,G.E., 2000. Carotid body mechanisms in acclimatization to hypoxia. Resp. Physiol. 121, 237-246.

Buckler,K.J., Williams,B.A., and Honore,E., 2000. An oxygen-, acid- and anaestheticsensitive TASK-like background potassium channel in rat arterial chemoreceptor cells. J. Physiol 525, 135-142.

Carpenter,E., Bee,D., and Peers,C., 1998. Ionic currents in carotid body type I cells isolated from normoxic and chronically hypoxic adult rats. Brain Res. 811, 79-87.

Chou,C.L., Sham,J.S., Schofield,B., and Shirahata,M., 1998. Electrophysiological and immunocytological demonstration of cell-type specific responses to hypoxia in the adult cat carotid body. Brain Res. 789, 229-238.

Chou,C.L. and Shirahata,M., 1996. Two types of voltage-gated K channels in carotid body cells of adult cats. Brain Res. 742, 34-42.

Coetzee,W.A., Amarillo,Y., Chiu,J., Chow,A., Lau,D., McCormack,T., Moreno,H., Nadal,M.S., Ozaita,A., Pountney,D., Saganich,M., Vega-Saenz,d.M., and Rudy,B., 1999. Molecular diversity of K+ channels. Ann. N. Y. Acad. Sci. 868:233-85., 233-285. 
Conforti,L., Bodi,I., Nis bet,J.W., and Millhorn,D.E., 2000. O2-sensitive K+ channels: role of the Kv1.2 -subunit in mediating the hypoxic response. J. Physiol 524, 783-793.

Conrad,P.W., Conforti,L., Kobayashi,S., Beitner-Johnson,D., Rust,R.T., Yuan,Y., Kim,H.W., Kim,R.H., Seta,K., and Millhorn,D.E., 2001. The molecular basis of O2sensing and hypoxia tolerance in pheochromocytoma cells. Comp Biochem. Physiol B Biochem. Mol. Biol. 128, 187-204.

Fu,X.W., Wang,D., Nurse,C.A., Dinauer,M.C., and Cutz,E., 2000. NADPH oxidase is an $\mathrm{O} 2$ sensor in airway chemoreceptors: evidence from $\mathrm{K}+$ current modulation in wildtype and oxidase-deficient mice. Proc. Natl. Acad. Sci. U. S. A 97, 4374-4379.

Ganfornina,M.D. and López Barneo,J., 1992a. Gating of $\mathrm{O}_{2}$-sensitive $\mathrm{K}^{+}$channels of arterial chemoreceptor cells and kinetic modifications induced by low $\mathrm{PO}_{2}$. J. Gen. Physiol. 100, 427-455.

Ganfornina,M.D. and López Barneo,J., 1992b. Potassium channel types in arterial chemoreceptor cells and their selective modulation by oxygen. J. Gen. Physiol. 100, 401-426.

Gonzalez,C., Almaraz,L., Obeso,A., and Rigual,R., 1994. Carotid body chemoreceptors: from natural stimuli to sensory discharges. Physiol. Rev. 74, 829-898.

Gutman,G.A., Chandy,K.G., Adelman,J.P., Aiyar,J., Bayliss,D.A., Clapham,D.E., Covarrubias,M., Desir,G.V., Furuichi,K., Ganetzky,B., Garcia,M.L., Grissmer,S., Jan,L.Y., Karschin,A., Kim,D., Kuperschmidt,S., Kurachi,Y., Lazdunski,M., Lesage,F., Lester,H.A., McKinnon,D., Nichols,C.G., O'Kelly,I., Robbins,J., Robertson,G.A., Rudy,B., Sanguinetti,M., Seino,S., Stuehmer,W., Tamkun,M.M., Vandenberg,C.A., Wei,A., Wulff,H., and Wymore,R.S., 2003. International Union of Pharmacology. XLI. Compendium of voltage-gated ion channels: potassium channels. Pharmacol. Rev. 55, 583-586. 
Hatton,C.J., Carpenter,E., Pepper,D.R., Kumar,P., and Peers,C., 1997. Developmental changes in isolated rat type I carotid body cell $\mathrm{K}+$ currents and their modulation by hypoxia. J Physiol 501, 49-58.

Hille,B., 2001. Ion channels of excitable membranes. Sinauer.

Hulme,J.T., Coppock,E.A., Felipe,A., Martens,J.R., and Tamkun,M.M., 1999. Oxygen sensitivity of cloned voltage-gated $\mathrm{K}(+)$ channels expressed in the pulmonary vasculature. Circ. Res. 85, 489-497.

Jerng,H.H., Pfaffinger,P.J., and Covarrubias,M., 2004. Molecular physiology and modulation of somatodendritic A-type potassium channels. Mol Cell Neurosci. 27, 343369.

Kaab,S., Miguel-Velado,E., Lopez-Lopez,J.R., and Perez-Garcia,M.T., 2005. Down regulation of kv3.4 channels by chronic hypoxia increases acute oxygen sensitivity in rabbit carotid body. J Physiol. 566, 395-408.

Kemp,P.J., 2006. Detecting acute changes in oxygen: will the real sensor please stand up? Exp Physiol. 91, 829-834.

Kuryshev,Y.A., Wible,B.A., Gudz,T.I., Ramirez,A.N., and Brown,A.M., 2001.

KChAP/Kvbeta1.2 interactions and their effects on cardiac Kv channel expression. Am. J. Physiol Cell Physiol 281, C290-C299.

Lahiri,S., Roy,A., Baby,S.M., Hoshi,T., Semenza,G.L., and Prabhakar,N.R., 2006.

Oxygen sensing in the body. Prog. Biophys. Mol Biol 91, 249-286.

Li,Y.L. and Schultz,H.D., 2006. Enhanced sensitivity of Kv channels to hypoxia in the carotid body in heart failure: role of angiotensin II. J. Physiol. 575, 215-227. 
Lopez-Barneo,J., Lopez-Lopez,J.R., Urena,J., and Gonzalez,C., 1988.

Chemotransduction in the carotid body: $\mathrm{K}+$ current modulated by $\mathrm{PO} 2$ in type I chemoreceptor cells. Science $241,580-582$.

Lopez-Barneo,J., Pardal,R., and Ortega-Saenz,P., 2001. Cellular mechanism of oxygen sensing. Annu. Rev. Physiol 63, 259-287.

López-López,J.R., De Luis,D.A., and Gonzalez,C., 1993. Properties of a transient K+ current in chemoreceptor cells of rabbit carotid body. J. Physiol. 460, 15-32.

López-López,J.R., Gonzalez,C., and Pérez-García,M.T., 1997. Properties of ionic currents from isolated adult rat carotid body chemoreceptor cells: effect of hypoxia. J. Physiol 499, 429-441.

López-López,J.R., Gonzalez,C., Ureña,J., and López-Barneo,J., 1989. Low pO 2 selectively inhibits $\mathrm{K}$ channel activity in chemoreceptor cells of the mammalian carotid body. J. Gen. Physiol. 93, 1001-1015.

Lopez-Lopez,J.R., Perez-Garcia,M.T., Sanz-Alfayate,G., Obeso,A., and Gonzalez,C., 2003. Functional identification of Kvalpha subunits contributing to the O2-sensitive $\mathrm{K}+$ current in rabbit carotid body chemoreceptor cells. Adv. Exp. Med. Biol. 536:33-9., 3339.

Martens,J.R., Kwak,Y.G., and Tamkun,M.M., 1999. Modulation of Kv channel alpha/beta subunit interactions. Trends Cardiovasc. Med. 9, 253-258.

McCrossan,Z.A. and Abbott,G.W., 2004. The MinK-related peptides. Neuropharmacol. $47,787-821$.

Otsubo,T., Yamaguchi,S., Okumura,M., and Shirahata,M., 2006. Differential expression of oxygen sensitivity in voltage-dependent $\mathrm{K}$ channels in inbred strains of mice. Adv. Exp Med Biol 580, 209-214. 
Overholt,J.L., Ficker,E., Yang,T., Shams,H., Bright,G.R., and Prabhakar,N.R., 2000. HERG-Like potassium current regulates the resting membrane potential in glomus cells of the rabbit carotid body. J. Neurophysiol. 83, 1150-1157.

Pardal,R., Ludewig,U., Garcia-Hirschfeld,J., and Lopez-Barneo,J., 2000. Secretory responses of intact glomus cells in thin slices of rat carotid body to hypoxia and tetraethylammonium. Proc. Natl. Acad. Sci. USA 97, 2361-2366.

Patel,A.J. and Honore,E., 2001. Molecular physiology of oxygen-sensitive potassium channels. Eur. Respir. J 18, 221-227.

Peers,C., 1990. Hypoxic suppression of $\mathrm{K}^{+}$currents in type I carotid body cells: selective effect on the $\mathrm{Ca}^{2(+)}$-activated $\mathrm{K}^{+}$current. Neurosci. Lett. 119, 253-256.

Peers,C., 1997. Oxygen-sensitive ion channels. Trends Pharmacol. Sci. 18, 405-408.

Peers,C. and Buckler,K.J., 1995. Transduction of Chemostimuli by the Type I Carotid Body Cell. J. Memb. Biol. 144, 1-9.

Peers,C. and O'Donnell,J., 1990. Potassium currents recorded in type I carotid body cells from the neonatal rat and their modulation by chemoexcitatory agents. Brain Res. $522,259-266$.

Peers,C. and Kemp,P., 2001. Acute oxygen sensing: diverse but convergent mechanisms in airway and arterial chemoreceptors. Resp. Res. 2, 145-149.

Perez-Garcia,M.T., Colinas,O., Miguel-Velado,E., Moreno-Dominguez,A., and LopezLopez,J.R., 2004. Characterization of the Kv channels of mouse carotid body chemoreceptor cells and their role in oxygen sensing. J. Physiol. 557, 457-471.

Pérez-García,M.T. and López-López,J.R., 2000a. Are Kv channels the essence of O2 sensing? Circ. Res. 86, 490-491. 
Perez-Garcia,M.T., Lopez-Lopez,J.R., and Gonzalez,C., 1999. Kvbeta1.2 subunit coexpression in HEK293 cells confers O2 sensitivity to kv4.2 but not to Shaker channels. J. Gen. Physiol 113, 897-907.

Pérez-García,M.T., López-López,J.R., Riesco,A.M., Hoppe,U.C., Marban,E., Gonzalez,C., and Johns,D.C., 2000b. Viral gene transfer of dominant-negative Kv4 construct suppresses an O2- sensitive $\mathrm{K}+$ current in chemoreceptor cells. J. Neurosci. 20, 5689-5695.

Pérez-García,M.T., Obeso,A., López-López,J.R., Herreros,B., and Gonzalez,C., 1992. Characterization of cultured chemoreceptor cells dissociated from adult rabbit carotid body. Am. J. Physiol. 263, C1152-9.

Platoshyn,O., Yu,Y., Golovina,V.A., McDaniel,S.S., Krick,S., Li,L., Wang,J.Y., Rubin,L., and Yuan,J.X.J., 2001. Chronic hypoxia decreases KV channel expression and function in pulmonary artery myocytes. Am. J. Physiol. 280, L801-L812.

Pozeg,Z.I., Michelakis,E.D., McMurtry,M.S., Thebaud,B., Wu,X.C., Dyck,J.R.B., Hashimoto,K., Wang,S., Moudgil,R., Harry,G., Sultanian,R., Koshal,A., and Archer,S.L., 2003. In Vivo Gene Transfer of the O2-Sensitive Potassium Channel Kv1.5 Reduces Pulmonary Hypertension and Restores Hypoxic Pulmonary Vasoconstriction in Chronically Hypoxic Rats. Circulation 107, 2037-2044.

Riesco-Fagundo,A.M., Pérez-García,M.T., Gonzalez,C., and López-López,J.R., 2001. O2 Modulates Large-Conductance Ca2+-Dependent K+ Channels of Rat Chemoreceptor Cells by a Membrane-Restricted and CO-Sensitive Mechanism. Circ Res 89, 430-436.

Rudy,B. and McBain,C.J., 2001. Kv3 channels: voltage-gated K+ channels designed for high-frequency repetitive firing. Trends Neurosci. 24, 517-526. 
Sanchez,D., Lopez-Lopez,J.R., Perez-Garcia,M.T., Sanz-Alfayate,G., Obeso,A., Ganfornina,M.D., and Gonzalez,C., 2002. Molecular identification of Kvalpha subunits that contribute to the oxygen-sensitive $\mathrm{K}(+)$ current of chemoreceptor cells of the rabbit carotid body. J. Physiol 542, 369-382.

Sawamoto,K., Nakao,N., Kobayashi,K., Matsushita,N., Takahashi,H., Kakishita,K., Yamamoto,A., Yoshizaki,T., Terashima,T., Murakami,F., Itakura,T., and Okano,H., 2001. Visualization, direct isolation, and transplantation of midbrain dopaminergic neurons. Proc. Natl. Acad. Sci. USA 98, 6423-6428.

Takahashi,T., Osanai,S., Nakano,H., Ohsaki,Y., and Kikuchi,K., 2005. Doxapram stimulates the carotid body via a different mechanism than hypoxic chemotransduction. Respir. Physiol Neurobiol. 147, 1-9.

Thompson,R.J., Farragher,S.M., Cutz,E., and Nurse,C.A., 2002. Developmental regulation of $\mathrm{O}(2)$ sensing in neonatal adrenal chromaffin cells from wild-type and NADPH-oxidase-deficient mice. Pflugers Arch. 444, 539-548.

Thompson,R.J., Jackson,A., and Nurse,C.A., 1997. Developmental loss of hypoxic chemosensitivity in rat adrenomedullary chromaffin cells. J. Physiol 498 ( Pt 2), 503510.

Thompson,R.J. and Nurse,C.A., 1998. Anoxia differentially modulates multiple K+ currents and depolarizes neonatal rat adrenal chromaffin cells. J. Physiol 512, 421-434.

Wang,D., Youngson,C., Wong,V., Yeger,H., Dinauer,M.C., Vega-Saenz,M.E., Rudy,B., and Cutz,E., 1996. NADPH-oxidase and a hydrogen peroxide-sensitive $\mathrm{K}+$ channel may function as an oxygen sensor complex in airway chemoreceptors and small cell lung carcinoma cell lines. Proc. Natl. Acad. Sci. USA 93, 13182-13187. 
Wang,Z.Y. and Bisgard,G.E., 2002. Chronic hypoxia-induced morphological and neurochemical changes in the carotid body. Microsc. Res. Tech. 59, 168-177.

Weir,E.K. and Archer,S.L., 1995. The mechanism of acute hypoxic pulmonary vasoconstriction: the tale of two channels. FASEB J. 9, 183-189.

Wyatt,C.N., Wright,C., Bee,D., and Peers,C., 1995. O $\mathrm{O}_{2}$-sensitive $\mathrm{K}^{+}$currents in carotid body chemoreceptor cells from normoxic and chronically hypoxic rats and their roles in hypoxic chemotransduction. Proc. Natl. Acad. Sci. USA, 92, 295-299.

Yamaguchi,S., Lande,B., Kitajima,T., Hori,Y., and Shirahata,M., 2004. Patch clamp study of mouse glomus cells using a whole carotid body. Neurosci. Lett. 357, 155-157.

Youngson,C., Nurse,C., Yeger,H., and Cutz,E., 1993. Oxygen sensing in airway chemoreceptors. Nature 365, 153-155.

Yuan,J.X., 2001. Oxygen-sensitive K(+) channel(s): where and what? Am J Physiol Lung Cell Mol Physiol 281, L1345-L 1349. 


\section{Figure Legends}

Figure 1. A. Phylogenetic unrooted tree derived from maximum likelyhood analysis of the amino acid sequences of the region encompassing the S5-P-S6 domains of representative examples of human $\mathrm{K}$ channel subunits. Local bootstrap proportions values above $50 \%$ are indicated in each branch. The scale bar represents branch length (number of amino acid substitutions/100 residues). B. Molecular composition of $\mathrm{Kv}$ channels. $\mathrm{Kv}$ channels are heterotetramers of principal ( $\alpha$ ) subunits and several auxiliary subunits that affect cell surface expression or modify specific functional properties of the pore-forming a subunits. The scheme shows the location (transmembrane or intracellular) of the Kv channels auxiliary subunits and their proposed binding site in the Kv a subunit.

Figure 2. Suppression of Kv4 channels modifies rabbit CB chemoreceptor cells excitability. Current-clamp experiments using the perforated patch technique were performed in control cells and in Kv4.xDN infected cells. The left part of the figure shows the values of resting membrane potential in a control cell during the application of a hypoxic solution and a solution containing $1 \mathrm{mM}$ 4-AP. Simultaneous register of the $\mathrm{PO}_{2}$ value in the bath solution is shown in the lower part of the graph. The average depolarization obtained with these two manoeuvres is represented in the inset as $\Delta \mathrm{Vm}\left({ }^{* *} p<0.001\right)$. The effect of hypoxia was studied using the same experimental protocol in a Kv4.xDN infected cell (right panel). Resting membrane potential values were more depolarized in these cells. In addition, hypoxia did not produce any significant change on the resting membrane potential in all the Kv4.xDN studied, as shown in the inset. (Modified from Perez-Garcia, M. T. et al. 2000). 
Figure 3. Scheme of the proposed model for the effects of acute and chronic hypoxia on rabbit $\mathrm{CB}$ chemoreceptor cells. Kv4 channels are the targets of acute hypoxic inhibition, leading to cell depolarization, opening of voltage-dependent $\mathrm{Ca}^{2+}$ channels and increased neurotransmitter release. Under prolonged (chronic) hypoxic exposure, a decreased expression of Kv3.4 channels trough a yet undetermined pathway takes place. This down-regulation of Kv3.4 channels determines a larger contribution of Kv4 channels to the total outward current that could explain the sensitization of the response of chemoreceptor cells to acute hypoxic episodes under these conditions (see text for more details). 